\title{
Mitochondrial Dysfunction of In Vitro Grown Rabbit Oocytes Results in Preimplantation Embryo Arrest After Activation
}

\author{
Hiroyuki KANAYA ${ }^{1)}$, Shu HASHIMOTO' ${ }^{2)}$, Takeshi TERAMURA ${ }^{1)}$, \\ Yoshiharu MORIMOTO'), Kazuya MATSUMOTO'), Kazuhiro SAEKI'), \\ Akira IRITANI') and Yoshihiko HOSOI ${ }^{1)}$
}

1)Department of Biology-Oriented Science and Technology, Division of Genetic Engineering, Kinki University, Wakayama 649-6493 and ${ }^{2)}$ IVF Namba Clinic, 1-17-28 Minamihorie, Osaka 550-0015, Japan

\begin{abstract}
To clarify the mechanism that impairs development of in vitro grown (IVG) oocytes, we assessed whether the developmental disability of IVG oocytes is caused by cytoplasmic dysfunction. First, we assessed the cleavage of nuclear-substituted oocytes cultured in vitro. The nuclei, but not the cytoplasm, of the IVG oocytes were able to support subsequent cleavage after artificial activation. The mitochondrial activity of the oocytes increased as the follicles grew. However, the mitochondrial activity of the IVG oocytes was significantly lower than that of ovulated oocytes and oocytes recovered from follicles with diameters of more than $300 \mu \mathrm{m}$. Furthermore, the expression levels of mitochondrial transcriptional factor A (TFAM) in the oocytes increased in a similar manner. However, the expression levels of TFAM in the IVG oocytes was significantly lower than that of ovulated oocytes and oocytes recovered from follicles with diameters of more than $300 \mu \mathrm{m}$. Taken together, these results indicate that the low developmental competence of IVG oocytes is caused by a cytoplasm deficiency due to low mitochondrial activity.

Key words: In vitro growth, Growing oocytes, Mitochondria, Mitochondrial transcriptional factor A (TFAM), Rabbit
\end{abstract}

(J. Reprod. Dev. 53: 631-637, 2007)

$\mathbf{T}$ he developmental competence of in vitro grown (IVG) oocytes after in vitro fertilization (IVF) is low compared with that of fully grown oocytes in mice [1], cattle [2] and rabbits (our unpublished data). This low developmental competence is believed to be caused by cytoplasmic dysfunction during in vitro growth. Oocytes contain a pool of non-replicating yet functional mitochondria from which all cells of the resultant embryos directly inherit their own complements. Ooplasmic mitochondrial metabolism has recently been shown

Accepted for publication: January 28, 2007

Published online: February 23, 2007

Correspondence: S. Hashimoto

(e-mail: hashimoto@ivfnamba.com) to be necessary for initiation [3] and progression [4] of preimplantation embryo development in the mouse. Age-related morphological changes have been reported in human oocytes [5], and these changes may correlate with the progressive agerelated decline in mitochondrial membrane potential that has been reported relative to embryo cell number [6]. Furthermore, the oocyte ATP level has been shown to correlate with postimplantation outcome [7] and to be involved in both arrest and resumption of meiosis in murine oocytes [8,9]. It has also been postulated that disordered spatial patterning of these organelles in the human oocyte could be inherited by daughter cells and result in local metabolic heterogeneities [10]. 
Mitochondrial dysfunction is likely detrimental to postimplantation development because all embryonic cells require mitochondria for cytoplasmic energy production and because mitochondria are important regulators of preimplantation embryo development.

Replication of mtDNA is dependent on nuclearencoded transcription and replication factors being translocated to the mitochondria [11]. Replication of mtDNA utilizes an RNA primer generated through transcription by mitochondrial transcription factor A (TFAM) [12] and the mitochondrial-specific polymerase gamma [13], which consists of the catalytic (POLG) and accessory (POLG2) subunits [14]. These two factors regulate the mtDNA copy number, which is correlated with the oxidative phosphorylation requirements of specific cells [15]. MtDNA replication occurs throughout oocyte growth in many species [16, 17]; however, based on observations in the frog [18], mouse [19, 20] and shrimp [21], it probably does not occur in the early cleavage stage of embryogenesis. The absence of mtDNA replication until the blastocyst stage has recently been confirmed in the mouse [22] and has also been reported in cattle [23]. However, a short burst of mtDNA turnover has been observed in mouse 2-cell embryos [24].

In the present study, the metaphase II spindles of IVG oocytes were transplanted into healthy enucleated ooplasts to determine whether the low developmental competence of IVG oocytes is caused by cytoplasmic dysfunction. The manipulated oocytes were then activated and cultured to the blastocyst stage. In addition, the mitochondrial activity of the IVG oocytes was assessed.

\section{Materials and Methods}

\section{In vitro growth of rabbit oocytes}

Multiple ovulation was induced in female New Zealand White rabbits by a single subcutaneous injection of 80-IU PMSG (Sankyo LifeTech, Kanagawa, Japan). The females were then intravenously administered 60 IU hCG (Teikoku Zoki, Tokyo, Japan) $72 \mathrm{~h}$ after the start of multipleovulation treatment [25].

Rabbit oocyte-granulosa cell complexes (OGCs) were recovered from follicles with diameters of
200-700 $\mu \mathrm{m}$ using 26-gauge needles, and oocytecumulus cell complexes (OCCs) were aspirated from follicles with diameters of more than $700 \mu \mathrm{m}$ using 26-gauge needles $14 \mathrm{~h}$ after hCG injection. Intact oocytes with intact granulosa cells were selected and randomly assigned to each treatment. In vitro culture of growing oocytes was carried out as reported previously with some modifications [26]. Briefly, OGCs were recovered from follicles with diameters of less than $300 \mu \mathrm{m}$ and cultured in minimum essential medium alpha medium ( $\alpha$ MEM, 11900-024; Invitrogen, Carlsbad, CA, USA) supplemented with $3 \mathrm{mg} / \mathrm{ml}$ BSA (A7638; SigmaAldrich, St. Louis, MO, USA), $50 \mu \mathrm{g} / \mathrm{ml}$ Ascorbic acid (A4544; Sigma-Aldrich), Insulin-TransferrinSelenium-A (51300-044; Invitrogen), and 2\% PVP (PVP360; Sigma-Aldrich) at $37 \mathrm{C}$ under $5 \% \mathrm{CO}_{2}$ with saturated humidity for 8 days. OCCs were recovered from follicles with diameters of more than $700 \mu \mathrm{m}$ and matured in TCM 199 (680557; Nissui Pharmaceutical, Tokyo, Japan) supplemented with $10 \mathrm{ng} / \mathrm{ml}$ EGF (E9644; SigmaAldrich), and $0.1 \mu \mathrm{M}$ estradiol-17 $\beta$ (E-8875; SigmaAldrich) at $37 \mathrm{C}$ under $5 \% \mathrm{CO}_{2}$ with saturated humidity for $12 \mathrm{~h}$. The mean diameter of the growing oocytes recovered from follicles with diameters of less than $300 \mu \mathrm{m}$ was $91.3 \pm 4.1 \mu \mathrm{m}$. Ten percent of the cultured oocytes $(100 / 964)$ survived and developed to $112.6 \pm 10.5 \mu \mathrm{m}$ in diameters after culture. These in vitro grown oocytes were used in the following experiment.

\section{Nuclear substitution of oocytes}

IVG oocytes were transferred to a droplet of M2 medium containing $10 \mu \mathrm{g} / \mathrm{ml}$ Hoechst 33342 (B2261; Sigma-Aldrich) and $7.5 \mu \mathrm{g} / \mathrm{ml}$ cytochalasin B (C6762; Sigma-Aldrich). The chromosomespindle complex and first polar body, which can be visualized with Hoechst 33342 under UV light, were drawn into a pipette along with a small amount of accompanying ooplasm using a Piezo drive system. Ovulated oocytes were enucleated in the same manner. The spindle of the IVG oocytes were injected into the perivitelline spaces of enucleated ovulated oocytes. The spindles of ovulated oocytes were transferred into enucleated IVG oocytes. The reconstructed oocytes were transferred and cultured in TCM 199 medium supplemented with 0.3\% BSA (199BSA) containing 2 mM 6-DMAP (6-dimethylaminopurine, D2629; Sigma-Aldrich) under $5 \% \mathrm{CO}_{2}$ in air for $45 \mathrm{~min}$ to 
reduce MPF activity. The oocytes were transferred and cultured in 199BSA under $5 \% \mathrm{CO}_{2}$ in air until electrical fusion. The reconstructed oocytes were transferred into mannitol fusion media $(0.3 \mathrm{M}$ mannitol, $0.01 \%$ PVA, $1.7 \mathrm{mM} \mathrm{MgCl} 2 \cdot 6 \mathrm{H}_{2} \mathrm{O}$ ) at room temperature, aligned, and placed between the electrodes of an electric cell fusion processor (SSH10; Shimadzu, Kyoto, Japan). They were then fused with two $80-\mu \mathrm{sec}$ pulses of $3.0 \mathrm{kVDC} / \mathrm{cm}$, washed in 75,50 and $25 \%$ fusion medium, washed in M2 medium, and placed in 199BSA.

\section{Activation}

The fused oocytes were placed between the wire electrodes (500 $\mu \mathrm{m}$ apart) of an electroporator (FTC22S; Shimadzu) in mannitol activation media ( $0.3 \mathrm{M}$ mannitol, $0.01 \%$ BSA, $0.52 \mathrm{mM} \mathrm{MgSO}_{4}$ and $0.1 \mathrm{mM}$ $\mathrm{CaCl}_{2}$ ), artificially activated with two $30-\mu \mathrm{sec}$ pulses of $2.5 \mathrm{kV} / \mathrm{cm}$, and placed in 199BSA containing $7.5 \mu \mathrm{g} / \mathrm{ml}$ cytochalasin B for $30 \mathrm{~min}$. The activation procedure was repeated two or more times, and then the oocytes were placed in a drop of 199BSA containing $2 \mathrm{mM}$ 6-DMAP for $2 \mathrm{~h}$. Parthenogenesis was confirmed by detection of a pseudopronucleus. Parthenogenetic embryos were cultured in 199BSA.

\section{Measurement of the mitochondrial activity of oocytes}

Measurement of the mitochondrial activity of oocytes was performed as reported previously [27]. Oocytes were recovered from follicles with diameters of $200-700 \mu \mathrm{m}$, washed twice, and incubated for $15 \mathrm{~min}$ in M2 medium containing Rhodamine 123 (50 $\mu \mathrm{g} / \mathrm{ml}$; Molecular Probes, Eugene, OR, USA). They were than washed in M2 medium to remove traces of the dye, placed in a well dish with M2 medium, and observed with an inverted fluorescence microscope (High-sensitivity cooled CCD, VB-6010; Keyence, Osaka, Japan) equipped with excitation (500-524), beam splitter (520 nm), and emission (542/27-25) filter. Fluorescent JPEG images were obtained with a digital camera (Keyence), and measurements were obtained by counting the number of pixels (Fig. 1).

\section{Measurement of the mRNA in oocytes}

Follicles having diameters of 200-300, 300-500, 500-700 and more than $700 \mu \mathrm{m}$, ovulated oocytes, and cultured oocytes were collected, centrifuged and stored in liquid nitrogen for RNA extraction. Total RNA was extracted using RNAqueous-Micro
(Ambion, Austin, TX, USA) according to the manufacturer's instructions. Single strand cDNA was prepared from total RNA using random hexamers under standard conditions with a Superscript III Reverse Transcriptase Kit (Invitrogen). The cDNA from each sample was used for a quantitative PCR assay for mitochondrial transcriptional factor A (TFAM). PCR reactions to obtain the sequences of the rabbit homologs were performed with total cDNA using HotMaster Taq (Eppendorf, Hamburg, Germany) and the appropriate primers. All PCR primers were designed to span a putative exon-exon junction in the cDNA to avoid amplification of genomic DNA. The reaction profile was $2 \mathrm{~min}$ at $94 \mathrm{C}$ followed by 35 cycles of $94 \mathrm{C}$ for $20 \mathrm{sec}, 58 \mathrm{C}$ for $10 \mathrm{sec}$ and $70 \mathrm{C}$ for $20 \mathrm{sec}$.

The primers for the sequences were designed to amplify tfam (5-ACAACTACCCATATTTAAAGC3 and 5-TATAAGCTGAACGAGGTC-3). After PCR, amplicons were cloned using the pGEM-T Easy Vector System (Promega, Madison, WI, USA) and then sequenced using a Big Dye Terminator v3.1 Cycle Sequencing Kit (Applied Biosystems, Foster City, CA, USA).

Quantitative PCR was performed with oocyte cDNA using Perfect Real Time SYBR Green (Takara Bio, Ohtsu, Japan) and a 7300 Real-Time PCR System (Applied Biosystems). The PCR conditions were $95 \mathrm{C}$ for $5 \mathrm{~min}$ followed by 35 cycles of $95 \mathrm{C}$ for $30 \mathrm{sec}, 60 \mathrm{C}$ for $30 \mathrm{sec}$ and $72 \mathrm{C}$ for $30 \mathrm{sec}$. Reactions were replicated two times for three different samples prepared independently. The results were analyzed using the 7300 system SDS software (Applied Biosystems) and Microsoft Excel (Microsoft, Redmond, WA, USA). All experiments included negative controls consisting of no cDNA for each primer pair. The primers for real-time PCR were designed to span exons to distinguish cDNA from genomic DNA products. The primers were tfam (5-CCAGAGGCAAAAAATTCAGAGCTA-3 and 5-TCATATACCTTTTTCTCTGAATCAGGAA3).

\section{Assessment of spindle structure}

The shape and size of the meiotic spindle and chromosomal alignments of the IVG oocytes were imaged using $\beta$-tubulin and nuclear DNA staining as described previously [28, 29].

The oocytes were fixed individually in $4 \%$ paraformaldehyde (P6148; Sigma-Aldrich) in PBS 
Table 1. Developmental competence of nuclear-substituted oocytes after activation of parthenogenesis

\begin{tabular}{|c|c|c|c|c|c|c|}
\hline & \multicolumn{6}{|c|}{ No. $(\%)$ of embryos developed } \\
\hline & $\begin{array}{l}\text { No. of } \\
\text { oocytes }\end{array}$ & $\begin{array}{l}\text { Pronuclear } \\
\text { stage }\end{array}$ & $\begin{array}{l}\text { 4-cell } \\
\text { stage }\end{array}$ & $\begin{array}{l}\text { 8-16-cell } \\
\text { stage }\end{array}$ & $\begin{array}{l}\text { Morula } \\
\text { stage }\end{array}$ & $\begin{array}{c}\text { Blastocyst } \\
\text { stage }\end{array}$ \\
\hline Ovulated oocytes & 23 & $21(91)$ & $18(78)$ & $14(60)$ & $13(56)$ & $9(39)$ \\
\hline Reconstituted oocytes with the cytoplasm of IVG oocytes & 17 & $1(5)$ & $0 \quad(0)$ & $0 \quad(0)$ & $0 \quad(0)$ & $0 \quad(0)$ \\
\hline Reconstructed oocytes with the nuclei of IVG oocytes & 20 & $15(75)$ & $10(50)$ & $6(30)$ & $4(20)$ & $15)$ \\
\hline
\end{tabular}

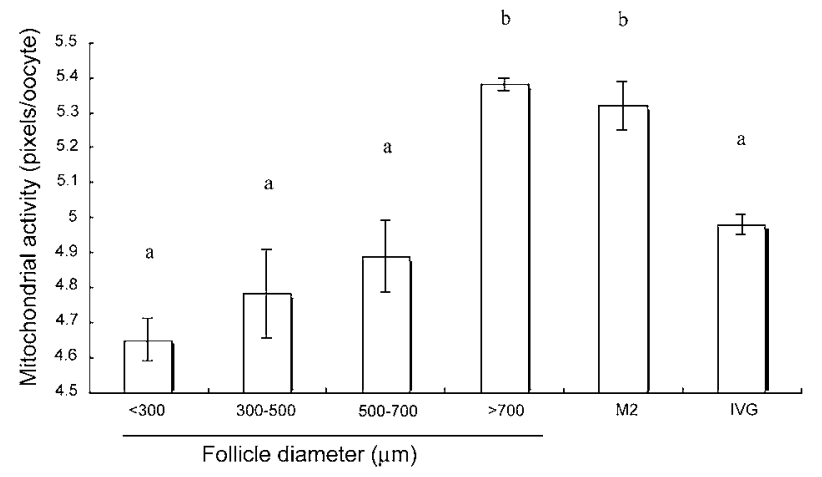

Fig. 1. Mitochondrial activity of oocytes from growing follicles, ovulated oocytes (MII) and in vitro grown oocytes. <300: Oocytes recovered from follicles with diameters of less than $300 \mu \mathrm{m}$. 300-500: Oocytes recovered from follicles with diameters of 300-500 $\mu \mathrm{m}$. 500-700: Oocytes recovered from follicles with diameters of 500-700 $\mu \mathrm{m}$. >700: Oocytes recovered from follicles with diameters of more than $700 \mu \mathrm{m}$. IVG: In vitro grown oocytes. M2: Ovulated oocytes. ${ }^{\mathrm{ab}} \mathrm{P}<0.05$.

for $2 \mathrm{~h}$, treated overnight with $0.1 \%$ Triton $\mathrm{X}-100$ in PBS, and incubated in blocking solution (PBS containing $5 \mathrm{mg} / \mathrm{ml}$ of BSA) for $30 \mathrm{~min}$. They were then incubated with anti- $\beta$-tubulin antibody in PBS (1:200; Sigma-Aldrich) for $1 \mathrm{~h}$ at $37 \mathrm{C}$, washed for 1 $\mathrm{h}$, and labeled with fluorescein isothiocyanateconjugated goat anti-mouse IgG (1:1,000; SigmaAldrich) in PBS-Tween for $1 \mathrm{~h}$. Subsequently, they were washed, stained with $10 \mu \mathrm{g} / \mathrm{ml}$ DAPI for examination of chromosomes, and observed with a fluorescent microscope (Axiophot 2, Carl Zeiss, Oberkochen, Germany) with an appropriate filter set. Fluorescent images were captured, and measurements were obtained by counting the number of pixels using imaging software (Image J).

Statistical analysis was performed using Fisher's protected least significant difference (PLSD) test following analysis of variance (ANOVA) or Student's $t$-test using the StatView program, version 5.0 (SAS Institute, Cary, NC, USA).

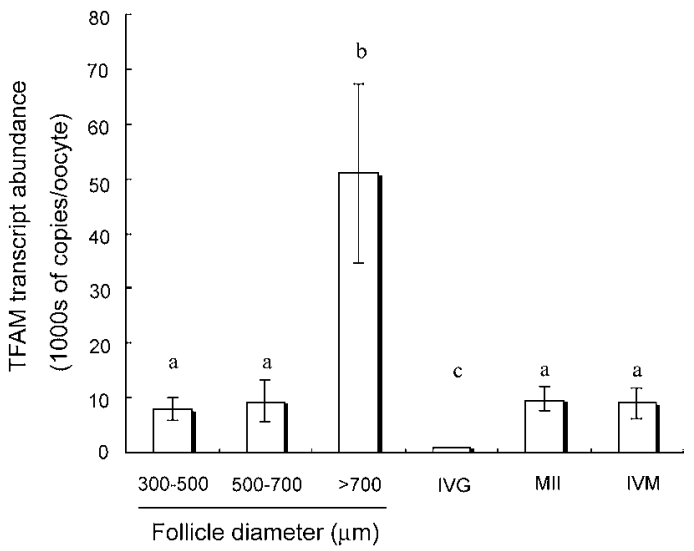

Fig. 2. Expression levels of TFAM in oocytes from growing follicles, in vitro-grown (IVG) oocytes, ovulated oocytes (MII), and in vitro matured (IVM) oocytes. ${ }^{\text {abc }} \mathrm{P}<0.05$.

\section{Results}

In vitro development of nuclear-substituted oocytes after activation

Reconstituted oocytes containig the cytoplasm of IVG oocytes and the nucleus of ovulated oocytes were incapable of developing after activation of parthenogenesis (Table 1). On the other hand, reconstructed oocytes containing the nucleus of IVG oocytes and cytoplasm of ovulated oocytes were capable of developing to blastocyst stage embryos after activation of parthenogenesis. Notably, reconstructed oocytes containing the cytoplasm of IVG oocytes were incapable of reaching the pronuclear stage.

\section{Mitochondrial activity of oocytes}

The mitochondrial activity of oocytes increased with increasing follicle diameter (Fig. 1). However, the mitochondrial activity of the IVG oocytes was 
a

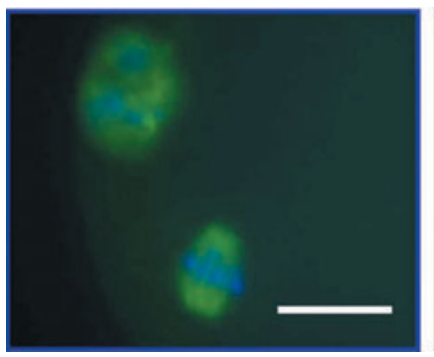

b

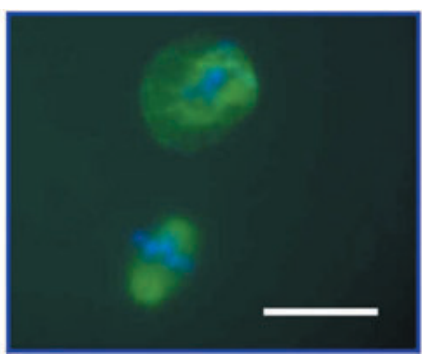

C

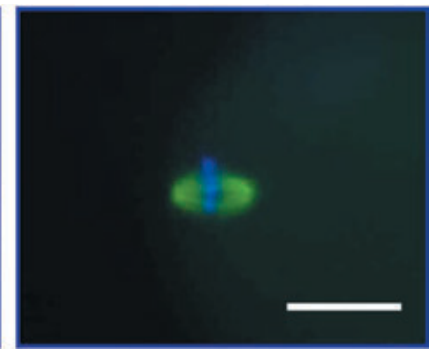

Fig. 3. Meiotic spindle configurations of a) ovulated oocytes, b) in vitro-matured oocytes, and c) reconstructed oocytes containing the nuclei of IVG oocytes and cytoplasm of ovulated oocytes. The images depict barrel-shaped spindles with normal chromosomal alignments in the oocytes, $\beta$-tubulins (green) and chromosomes (blue). Scale bars are $30 \mu \mathrm{m}$.

significantly lower than the mitochondrial activities of the ovulated and in vitro-matured oocytes $(\mathrm{P}<0.05)$. The expression level of the mRNA of TFAM increased with increasing follicle diameter (Fig. 2). On the other hand, the expression level of the IVG oocytes was significantly lower than the levels of the ovulated oocytes and oocytes recovered from follicles with diameters of 300-500, 500-700, and more than $700 \mu \mathrm{m}$.

\section{Assessment of spindle structure}

The meiotic spindle configuration of the IVG oocytes after nucleus replacement was similar to that of ovulated oocytes (Fig. 3).

\section{Discussion}

The preceding results clearly indicate that developmental arrest of the IVG oocytes was caused by the low activities of their mitochondria. Furthermore, the ATP content of recipient-mouse MII-stage oocytes can be increased by mitochondrial infusion [29], and transfused mitochondria can survive embryonic development and undergo replication [30]. In addition, the nuclear replacement technique can support development of the nuclei of cells with mitochondria damage [31]. In this study, developmental arrest was reversed once the nucleus of an IVG oocyte was transplanted into ovulated ooplasm. Thus, mitochondria damaged during in vitro growth may cause developmental arrest in IVG oocytes. This hypothesis is supported by the finding that the mitochondrial activity of growing oocytes increased with increasing follicle diameter; however, the mitochondrial activities of the IVG oocytes were significantly lower than those of the oocytes that were not grown in vitro. Replication of mtDNA is dependent on nuclearencoded transcription and replication factors being translocated to the mitochondria [11]. Replication of mtDNA utilizes an RNA primer generated through transcription by TFAM. Quantitative analysis of TFAM also indicated that replication of mtDNA in growing oocytes increased as the follicles grew. However, the level of TFAM mRNA in the IVG oocytes was extremely low. In this study, rabbit oocytes were cultured under $20 \%$ oxygen tension. Higher oxygen tension during in vitro culture of mammalian embryos has been suggested to cause developmental arrest as a result of the generation of reactive oxygen species in cells [32]. Thus, the mitochondria of IVG oocytes might be damaged by in vitro culture under high oxygen concentration conditions.

Segregation of meiotic chromosomes/ chromatids depends on their correct binding to the fibers of the meiotic spindle [33]. Although the dynamics of spindle function are unclear, the polymerization of spindle microtubules appears to depend on ATP $[34,35]$. Mitochondria are the major organelles providing ATP. Mitochondrial DNA is easily damaged, and the consequence of this damage is underproduction of ATP, which results in respiratory chain defects [36]. Immunofluorescent images of the meiotic spindles and chromosomes of IVG oocytes suggested that there was sufficient ATP in the cytoplasm as a consequence of nuclear replacement. These data 
suggest that the membrane potential of the mitochondria in the cytoplasm of the ovulated oocytes were intact, resulting in normal chromosomal alignments.
The results of the present study indicate that the developmental competence of the IVG oocytes was impaired by mitochondrial dysfunction due to damage to the mitochondria during in vitro culture.

\section{References}

1. Eppig JJ, O'Brien MJ. Development in vitro of mouse oocytes from primordial follicles. Biol Reprod 1996; 54: 197-207.

2. Hirao $Y$, Itoh T, Shimizu M, Iga K, Aoyagi K, Kobayashi M, Kacchi M, Hoshi H, Takenouchi N. In vitro growth and development of bovine oocytegranulosa cell complexes on the flat substratum: effects of high polyvinylpyrrolidone concentration in culture medium. Biol Reprod 2004; 70: 83-91.

3. Dumollard R, Marangos P, Fitzharris G, Swann K, Duchen M, Carroll J. Sperm-triggered $\left[\mathrm{Ca}^{2+}\right]$ oscillations and $\mathrm{Ca}^{2+}$ homeostasis in the mouse egg have an absolute requirement for mitochondrial ATP production. Development 2004; 131: 3057-3067.

4. Lane M, Gardner DK. Mitochondrial malateaspartate shuttle regulates mouse embryo nutrient consumption. J Biol Chem 2005; 280: 18361-18367.

5. de Bruin JP, Dorland M, Spek ER, Posthuma G, van Haaften $M$, Looman CW, te Velde ER. Agerelated changes in the ultrastructure of the resting follicle pool in human ovaries. Biol Reprod 2004; 70: 419-424.

6. Wilding $M$, Dale $B$, Marino $M$, di Matteo $L$, Alviggi C, Pisaturo ML, Lombardi L, De Placido G. Mitochondrial aggregation patterns and activity in human oocytes and preimplantation embryos. Hum Reprod 2001; 16: 909-917.

7. Van Blerkom J, Davis PW, Lee J. ATP content of human oocytes and developmental potential and outcome after in-vitro fertilization and embryo transfer. Hum Reprod 1995; 10: 415-424.

8. Downs SM. The influence of glucose, cumulus cells, and metabolic coupling on ATP levels and meiotic control in the isolated mouse oocyte. Dev Biol 1995; 167: 502-512.

9. Downs SM, Mastropolo M. The participation of energy substrates in the control of meiotic maturation in murine oocytes. Dev Biol 1994; 162: 154-168.

10. Van Blerkom J, Davis P, Alexander S. Differential mitochondrial distribution in human pronuclear embryos leads to disproportionate inheritance between blastomeres: relationship to microtubular organization, ATP content and competence. Hum Reprod 2000; 15: 2621-2633.

11. Clayton DA. Transcription and replication of mitochondrial DNA. Hum Reprod 2000; 15 (Suppl 2) 11-17.
12. Larsson NG, Wang J, Wilhelmsson $\mathbf{H}$, Oldfors $A$, Rustin P, Lewandoski M, Barsh GS, Clayton DA. Mitochondrial transcription factor A is necessary for mtDNA maintenance and embryogenesis in mice. Nat Genet 1998; 18: 231-236.

13. Hubscher U, Kuenzle CC, Spadari S. Functional roles of DNA polymerases beta and gamma. Proc Natl Acad Sci USA 1979; 76: 2316-2320.

14. Gray $\mathbf{H}$, Wong TW. Purification and identification of subunit structure of the human mitochondrial DNA polymerase. J Biol Chem 1992; 267: 5835-5841.

15. Moyes CD, Battersby BJ, Leary SC. Regulation of muscle mitochondrial design. J Exp Biol 1998; 201: 299-307.

16. Jansen RP, de Boer $\mathbf{K}$. The bottleneck: mitochondrial imperatives in oogenesis and ovarian follicular fate. Mol Cell Endocrinol 1998; 145: 81-88.

17. Smith LC, Alcivar AA. Cytoplasmic inheritance and its effects on development and performance. $J$ Reprod Fertil Suppl 1993; 48: 31-43.

18. El Meziane A, Callen JC, Mounolou JC. Mitochondrial gene expression during Хenopus laevis development: a molecular study. EMBO J 1989; 8: 1649-1655.

19. Ebert KM, Liem H, Hecht NB. Mitochondrial DNA in the mouse preimplantation embryo. J Reprod Fertil 1988; 82: 145-149.

20. Piko L, Taylor KD. Amounts of mitochondrial DNA and abundance of some mitochondrial gene transcripts in early mouse embryos. Dev Biol 1987; 123: 364-374.

21. Vallejo CG, Lopez $\mathbf{M}$, Ochoa $\mathbf{P}$, Manzanares $\mathbf{M}$, Garesse R. Mitochondrial differentiation during the early development of the brine shrimp Artemia franciscana. Biochem J 1996; 314: 505-510.

22. Thundathil J, Filion F, Smith LC. Molecular control of mitochondrial function in preimplantation mouse embryos. Mol Reprod Dev 2005; 71: 405-413.

23. May-Panloup $P$, Vignon $X$, Chretien MF, Heyman Y, Tamassia M, Malthiery Y, Reynier P. Increase of mitochondrial DNA content and transcripts in early bovine embryogenesis associated with upregulation of mtTFA and NRF1 transcription factors. Reprod Biol Endocrinol 2005; 3: 65-72.

24. McConnell JM, Petrie L. Mitochondrial DNA turnover occurs during preimplantation development and can be modulated by environmental factors. Reprod Biomed Online 2004; 9: 
418-424.

25. Hashimoto S, Kimura K, Kuramochi T, Aoyagi K, Hirako M, Kawaguchi M, Iwata H Hirao M, Kitada K, Hirasawa K, Ueda M. Responsiveness of rabbits to superovulation treatment by single injection of follicle stimulating hormone with aluminum hydroxide gel. Mol Reprod Dev (in press).

26. Hashimoto S, Ohsumi K, Tsuji $Y$, Harauma N, Miyata Y, Fukuda A, Hosoi Y, Iritani A, Morimoto Y. Growing porcine oocyte-granulosa cell complexes acquired meiotic competence during in vitro culture. J Reprod Dev 2007; 53: 379-384.

27. Thouas GA, Trounson AO, Wolvetang EJ, Jones GM. Mitochondrial dysfunction in mouse oocytes results in preimplantation embryo arrest in vitro. Biol Reprod 2004; 71: 1936-1942.

28. Wang WH, Keefe DL. Prediction of chromosome misalignment among in vitro matured human oocytes by spindle imaging with the Polscope. Fertil Steril 2002; 78: 1077-1081.

29. Van Blerkom J, Sinclair J, Davis P. Mitochondrial transfer between oocytes: potential applications of mitochondrial donation and the issue of heteroplasmy. Hum Reprod 1998; 13: 2857-2868.

30. Barrit JA, Brenner CA, Malter HE, Cohen J.
Mitochondria in human offspring derived from ooplasmic transplantation: brief communication. Hum Reprod 2001; 16: 513-516.

31. Takeuchi T, Neri QV, Katagiri Y, Rosenwaks Z, Palermo GD. Effect of treating induced mitochondrial damage on embryonic development and epigenesis. Biol Reprod 2005; 72: 584-592.

32. Johnson MH, Nasr-Esfahani MH. Radical solutions and cultural problems: could free oxygen radicals be responsible for the impaired development of preimplantation mammalian embryos in vitro? Bioessays 1994; 16: 31-38.

33. Eichenlaub-Ritter U, Vogt E, Yin H, Gosden R. Spindles, mitochondria and redox potential in aging oocytes. Reprod Biomed Online 2003; 8: 145-158.

34. Van Blerkom J, Runner MN. Mitochondrial reorganization during resumption of arrested meiosis in the mouse oocyte. Am J Anat 1984; 171: 335-355.

35. Van Blerkom J. Microtubule mediation of cytoplasmic and nuclear maturation during the early stages of resumed meiosis in cultured mouse oocytes. Proc Natl Acad Sci USA 1991; 88: 5031-5035.

36. Wallace DC. Mitochondrial diseases in man and mouse. Science 1999; 283: 1482-1488. 